\section{LA POLÍTICA DE VIVIENDA EN ESPAÑA EN EL CONTEXTO EUROPEO. DEUDAS Y RETOS ${ }^{1}$}

Raquel Rodríguez A. ${ }^{2}$

\section{HOUSING POLICY IN SPAIN WITHIN THE EUROPEAN CONTEXT. DEBTS AND CHALLENGES ${ }^{1}$}

\author{
Raquel Rodríguez A. ${ }^{2}$
}

\begin{abstract}
Resumen
Un parque sobredimensionado y mal repartido, en el que las familias de mayor renta acaparan varias viviendas mientras existe población con problemas de acceso, la generación de tejidos urbanos de buena y mala calidad, con procesos de exclusión social endémicos, o la ausencia de alternativas para el acceso a la vivienda para los hogares que no tienen recursos para acceder a la compra son problemas comunes en materia de vivienda. En el ejemplo español, la garantía en el acceso a la vivienda sigue siendo una asignatura pendiente. La política de vivienda se ha condicionado al cumplimiento de doble objetivo: procurar una vivienda digna a todos los españoles, e impulsar la economía a través del fomento de la construcción, provocando un parque sobredimensionado,
\end{abstract}

\section{Abstract}

Common problems concerning housing in Spain include: overstocked and poorly distributed housing stock, where higher income families monopolize housing leaving groups of people with access problems; generation of good and bad quality urban fabric, including endemic social exclusion processes; or the absence of alternatives for people with little resources to buy a house. In Spain, secure access to housing is still an unresolved matter. Housing policy is conditioned to two objectives: giving access to decent houses to all Spaniards, and boosting the economy by promoting construction; thus creating an overstocked, underused and overvalued housing stock that is available to 
infrautilizado y sobrevalorado, pero en el que no toda la población tiene cabida. A través del análisis del parque de viviendas y de la política pública desarrollada desde la segunda mitad del siglo XX tanto en España como en el norte de Europa, se ahondará en las estrategias políticas que han provocado esta situación, acabando con algunos programas en funcionamiento que pueden dar pautas para avanzar en la solución del problema.

\section{PALABRAS CLAVE: VIVIENDA, EXCLUSIÓN SOCIAL, REHABILITACIÓN, CONSTRUCCIÓN.}

Fecha de recepción: 02.03.2010

Fecha de aceptación: 30.07.2010

1 Trabajo tutelado. Programa de Doctorado Periferias, Sostenibilidad y Vitalidad Urbana del Departamento de Urbanística y Ordenación del territorio de la Escuela Técnica Superior de Arquitectura de Madrid. Dirigido por Agustín Hernández Aja. Septiembre 2009.

2 Española. Arquitecta Urbanista, Escuela Técnica Superior de Arquitectura de Madrid. Profesora asociada, Departamento de Urbanística y Ordenación del territorio, Escuela Técnica Superior de Arquitectura de Madrid y Jefa de proyecto, Departamento de Ordenación del Territorio, PROES Consultores S.A. Correo electrónico: raquel.rodriguez@upm.es some groups of people. Through the analysis of the housing stock and housing policies developed in Spain and in the north of Europe since the second half of the XXth century, this paper studies the political strategies that caused this situation, ending with programs that may give guidelines for solving the problem.

\section{KEYWORDS: HOUSING, SOCIAL EXCLUSION, REHABILITATION, CONSTRUCTION.}

Received: 02.03.2010

Accepted: 30.07 .2010

1 Doctorate program Periferias, Sostenibilidad y Vitalidad Urbana, Department of Urban Studies and Land Planning, Madrid Higher Technical School of Architecture. Guided by Agustín Hernández Aja. September 2009.

2 Spanish. Architect, Madrid Higher Technical School of Architecture. Associated professor, Department of Urban Studies and Land Planning, Madrid Higher Technical School of Architecture. Project manager, Department of Urban Planning, PROES Consultores S.A.

Email: raquel.rodriguez@upm.es

ARTICLE: Housing policy in Spain within the european context. Debts and challenges / 


\section{Introducción}

La garantía en el acceso a la vivienda sigue siendo una asignatura pendiente en España. Las decisiones tomadas a nivel político no sólo han estado encaminadas a procurar una vivienda digna a todos los españoles, sino que desde la época del desarrollismo se ha utilizado la construcción residencial como motor económico. Como consecuencia de ello, y a pesar de tener el parque de viviendas de mayor tamaño, la garantía en el acceso sigue sin estar resuelta. El último informe de la Organización para la Cooperación y el Desarrollo Económico ${ }^{3}$ (OCDE) señala que España tiene las viviendas más caras de todos los países desarrollados en relación con los salarios existentes. Sin embargo, un excesivo precio de la vivienda podría ser un problema menor si existieran alternativas a la propiedad para acceder a la vivienda, o un parque de viviendas social que pudiera acoger a los hogares con mayores dificultades. También sería un problema diferente si el stock y el nivel de construcción de viviendas estuviese ajustado a las necesidades reales. Pero, como se puede apreciar en la Tabla 1, la situación ha llegado al límite de su capacidad, con un parque sobredimensionado, infrautilizado, al que sólo se accede a través de la propiedad, siendo el alquiler libre la forma de acceso residual para aquellos hogares que no tienen recursos para llegar a ser

3 Perspectives économiques de l'OCDE No. 85, juin 2009 propietarios y sin un parque social estable que permita dar soluciones rápidas a la población con mayores dificultades. En la última década hemos urbanizado un territorio, donde la población está agrupada en función de su nivel de renta, que en muchos casos no era necesario y, por tanto, no va a ser utilizado.

A partir de los países pertenecientes a la Unión Europea se ha hecho una selección de aquellos cuyo contexto social y económico es similar al español y cuyo estado actual del parque y las políticas de vivienda y/ o suelo demuestren la existencia de iniciativas que podrían servir de ejemplo para mejorar los déficits del parque español. Por tanto, han quedado fuera del estudio todos los países cuya incorporación a la Unión Europea ha sido posterior a 2005, países como Portugal, Italia, Bélgica y Grecia, donde la problemática es similar a la española, y Austria y Luxemburgo, dado que la información disponible era muy escasa.

Se buscará el origen de las diferencias entre ambos modelos, a través del análisis de las políticas de vivienda seguidas en España y en otros países europeos desde la segunda mitad del siglo XX hasta nuestros días. El estudio de la evolución y la toma de decisiones tendrá dos objetivos fundamentales: de- 


\section{PRINCIPALES INDICADORES DEL ESTADO DEL PARQUE DE VIVIENDAS EN LOS PAÍSES DE ESTUDIO}

\begin{tabular}{|c|c|c|c|c|c|c|c|c|c|}
\hline & $\mathrm{AL}$ & D & $\mathrm{E}$ & $\mathrm{Fl}$ & FR & $\mathrm{H}$ & I & RU & S \\
\hline Parque de viviendas total (Viv./1000hab.) 2007 & 485 & $456^{*}$ & 551 & $503^{*}$ & 508 & 422 & 400 & $424^{*}$ & $486^{*}$ \\
\hline Tamaño del hogar (2005) & 2.1 & 2.2 & 2.9 & 2.1 & 2.3 & 2.3 & 2.9 & 2.4 & 2.0 \\
\hline Capacidad del parque de viviendas para albergar hogares (2005) & 2.1 & 2.2 & 1.9 & 2.0 & 2.0 & 2.4 & 2.5 & 2.3 & 2.1 \\
\hline Construcción de viviendas (Viv./1000hab.) 2007 & $2.21^{*}$ & 4.33 & 13.8 & & $6.67^{*}$ & 4.9 & 16.5 & 3.67 & $2.96^{*}$ \\
\hline$\%$ de viviendas sociales construidas respecto del total (2007) & & $10 \%$ & $14 \%$ & & & $26 \%$ & $9 \%$ & $13 \%$ & $31 \% *$ \\
\hline$\%$ de viviendas vacías 2004 & $8 \%$ & $6 \%$ & $30 \%$ & $9 \%$ & $6 \%$ & $2 \%$ & $12 \%$ & $3 \%$ & $2 \%$ \\
\hline$\%$ de viviendas en propiedad, 2004 & $45 \%$ & $49 \%$ & $82 \%$ & $63 \%$ & $57 \%$ & $56 \%$ & $79 \%$ & $69 \%$ & $38 \%$ \\
\hline$\%$ de vivienda social existente dentro del parque de viviendas & $6 \%$ & $20 \%$ & $1 \%$ & $18 \%$ & $19 \%$ & $35 \%$ & $9 \%$ & $21 \%$ & $21 \%$ \\
\hline
\end{tabular}

TABLA 1

*2006. Al (Alemania), D (Dinamarca), E (España), FI (Finlandia), FR (Francia), H (Holanda), I (Irlanda), RU (Reino Unido), S (Suecia).

terminar las causas de la situación actual, que serán la base para buscar alternativas de actuación; y comprender y comparar los objetivos en materia de política de vivienda en el momento actual, con objeto de demostrar que mientras en otros países del entorno la situación ha ido incorporando nuevos retos y es capaz de afrontar cuestiones más complejas, en España la garantía en el acceso sigue siendo un problema prioritario e irresoluble. Por último, se detallan algunas prácticas o programas existentes en otros países que puedan ser de aplicación y que permitan corregir la situación a corto, medio o largo plazo ${ }^{4}$.

4 Aunque el contenido de aquella información no va a ofrecer los puntos débiles de dichas políticas, pudiendo correr el riesgo de plantear sólo buenas intenciones, no es objeto del presente trabajo el análisis de su implantación sino la búsqueda de ideas y ejemplos que puedan corregir la situación en España.

\section{Historia de la política de vivienda en Europa}

El problema de la vivienda en Europa es consecuencia de la inmigración campo ciudad producida por la revolución industrial. La masiva llegada de trabajadores del campo con el fin de acceder a un puesto de trabajo en el sector industrial satura las ciudades que crecen mucho más rápidamente en número de habitantes que en viviendas y en equipamientos. A finales del siglo XIX los gobier-

ARTíCULO: La política de vivienda en España en el contexto europeo. Deudas y Retos / 
nos de la Europa occidental ya han comenzado con el proceso de saneamiento de las ciudades (demolición de viviendas insalubres, creación de equipamientos, ensanchamientos de calles...) acompañándolo con la creación de una nueva legislación relativa a normas de construcción y urbanismo. Pero todas estas medidas no facilitan el acceso a la vivienda de la población de rentas más bajas. A principios del siglo XX comienzan a ponerse en marcha las políticas necesarias para dar solución al problema de alojamiento de los trabajadores sin recursos. En este momento se inician los programas de vivienda social en los países industrializados de Europa del norte, siendo una de sus primeras iniciativas la creación de viviendas. La oferta de vivienda social comienza en Suecia Dinamarca, Austria, Alemania, Francia, Holanda y Reino Unido. En algunos países, como Alemania, Holanda o los países escandinavos, la política se implanta rápidamente, de modo que al final de la $2^{\mathrm{a}}$ Guerra Mundial existe ya un parque social considerable. En 1919, el Reino Unido introduce la vivienda en la legislación, Housing and Town Planning Act. Sin embargo en Francia, a pesar de existir iniciativas en este terreno, la construcción masiva de vivienda social no se iniciará hasta los años 50 y $60^{5}$

5 Louvot-Runavot, Claudie, 2001.
El principio del siglo XX fue un periodo muy conflictivo políticamente y los condicionantes económicos hicieron difícil la construcción de todas las viviendas necesarias. En los años 30, con posterioridad a la crisis económica del 29, se generalizan las políticas de congelación de los alquileres que tenían como objetivo evitar la especulación y facilitar el acceso a la vivienda o el mantenimiento en ella a parte de la población. Esta iniciativa se generaliza en Europa durante los años $40^{6}$. La supuesta gran rentabilidad de la bolsa en los años 20, la posterior crisis del 29 y la congelación de los alquileres que protegía a los inquilinos de la especulación desanima a los inversores privados. Además, la participación activa de muchos países en la Segunda Guerra Mundial y las guerras civiles de España y Grecia hacen desaparecer parte del parque ya construido. Como consecuencia, a principios de los años 50 toda Europa sufre una gran escasez de viviendas ${ }^{7}$.

\section{LA RECONSTRUCCIÓN DESPUÉS DE LAS GRANDES GUERRAS}

Esta necesidad de viviendas es la causa directa del boom constructivo en los países de Europa del Norte, que se prolonga aproximadamente durante

\footnotetext{
$6 \quad$ En España se aprueba la congelación de los alquiler el 29 de marzo de 1947 (Ley del 31 de Diciembre de 1946).

7 Louvot-Runavot. Op cit.
} 
algo más de 30 años, ${ }^{8}$ pudiendo citar como causa principal la explosión demográfica posterior a la Segunda Guerra Mundial, y la posterior formación de hogares de dicha generación durante los años 70. Los primeros países en alcanzar el volumen necesario de construcción son Alemania y el Reino Unido. A finales de los años 70, la mayor parte del norte de Europa ha conseguido un parque adecuado en tamaño a las necesidades reales de la población.

A principios de los 50 surgen las ayudas a la vivienda. Con objeto de apoyar la construcción del stock necesario y facilitar el acceso a la vivienda a toda la población, los gobiernos europeos ponen en marcha una serie de ayudas que pueden clasificarse en tres tipos distintos ${ }^{9}$ :

- Ayuda a la producción, cuyo objetivo es el de reducir el coste de las inversiones en construcción de viviendas. En forma de subvenciones o bonificaciones en los intereses, es el tipo de ayuda más frecuente durante este periodo. En un primer momento estas ayudas se aplicaban sólo a la construcción del parque social. Posteriormente, se generalizan al mercado libre.

- Ayudas a la persona: son ayudas directas a los usuarios que no son capaces de soportar las cargas producidas por el gasto de la vivienda.

8 Ibid.

9 Parlamento Europeo (1996), W-14.
En un primer momento son más restringidas y sólo existían en algunos países. Desde los años 50 , las ayudas directas a las personas (familias de bajos ingresos) conviven con la construcción de un parque social de viviendas en Alemania, Finlandia y Bélgica. Sin embargo, estas ayudas tienen su origen mayoritariamente en la descongelación de los alquileres, que produjo subidas de precio por encima de la inflación y los salarios. En 1977 se crea en Francia el APL (Allocation Personelle au Logement), en Alemania en 1965 el Wohngeld. Durante los años 80 comenzarán a generalizarse y sustituirán paulatinamente a las ayudas a la producción, extendiéndose a los futuros propietarios.

- Ayudas fiscales que toman la forma de reducciones de impuestos. Aunque en Alemania este sistema surge en 1949, en la mayoría de los países se implanta mucho más tarde.

El parque de vivienda social en alquiler aumenta considerablemente gracias al impulso que se da a la construcción entre los años 50 y 80. Las ayudas a la producción subvencionaron entre el 30\% y el $50 \%$ de la construcción de viviendas que pasaban a formar parte del parque en alquiler con precios por debajo del mercado. Sin embargo, aunque la calidad de este tipo de viviendas estaba reglamentada la prioridad era el incremento del parque, por 
lo que no se prestó atención al tipo de tejido urbano que se generaba en estos momentos, que era de muy baja calidad y sin apenas servicios.

En Reino Unido, Holanda y Suecia no existía límite de renta para habitar las viviendas sociales, existiendo todavía grupos minoritarios de clase media alta que hacen uso de dicho parque. No obstante, en Irlanda o Alemania han existido siempre reglas estrictas para acceder a la vivienda social.

Durante los años 60, la inversión realizada en el incremento del parque de viviendas, la subida del nivel de renta de la población y el mantenimiento del alto nivel de la construcción hizo posible la desaparición de la congelación sobre los alquileres libres. Durante los años 70 en Alemania y Holanda, donde la tensión del mercado se había reducido y la inflación estaba dominada, el control sobre los alquileres se abandonó definitivamente. Pero hasta los años 80 no se extiende esta medida sobre la totalidad del parque en alquiler.

La congelación de los alquileres durante más de 30 años trajo consecuencias importantes sobre la ciudad, el parque de viviendas, y el tejido social que lo habitaba. Aunque esta medida había conseguido favorecer el acceso a la vivienda de las personas de rentas más bajas, también contribuyó a desanimar a la inversión privada. El parque en alquiler libre se fue deteriorando hasta convertirse en un stock de muy baja calidad, obsoleto y lleno de carencias. Además, como consecuencia directa del levantamiento del veto sobre los alquileres, éstos empiezan a subir de precio más rápidamente que la tasa de inflación y los sueldos. Para paliar este problema se crean las ayudas a la persona, que originariamente tenían como objetivo reducir el peso del incremento de la renta sobre las economías familiares. Sin embargo, esta medida no es suficiente. La renovación de este parque, normalmente localizado en las zonas más antiguas de la ciudad, provoca un aumento en los precios y una expulsión paulatina de la población residente.

La construcción masiva de viviendas en los países del sur de Europa es mucho más tardía. En España no se inicia hasta los años 60. Durante la misma época se aprueba la Ley 40/64 que mantuvo la congelación de los alquileres hasta 1985. Empero, como se puede apreciar en el Gráfico 1 y en el Gráfico 2, en España no existe un parque social propiamente dicho, tal como se entiende en el norte de Europa, es decir, un parque en alquiler con precios controlados que se ha ido construyendo poco a poco y que es gestionado por entidades públicas o privadas. Las promociones que podrían ser consideradas como parque social en España, viviendas protegidas o viviendas concertadas, salen al mercado directamente para su venta con un precio fijado por el gobierno por debajo de los precios del mercado. Hasta la aprobación del Plan de Vivienda 2005-2008, todas las viviendas protegidas dejaban de pertenecer al parque social desde el momento de su venta, debiendo reinvertir 


\section{PORCENTAJE DE VIVIENDA SOCIAL EN ALQUILER RESPECTO A LA TOTALIDAD DEL PARQUE 2007}

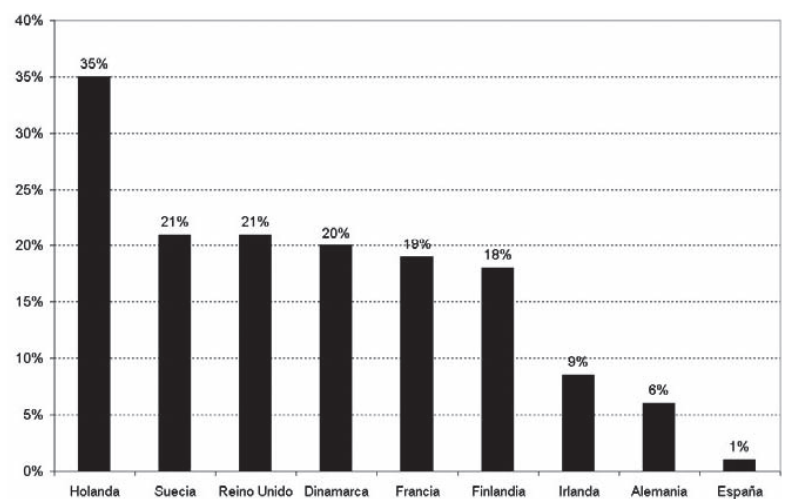

GRÁFICO 1

Fuente: CECODHAS (2007).

Elaboración propia.

constantemente para la construcción de un nuevo parque. Por tanto no existe un parque permanente, como en el resto de Europa, destinado a dar una respuesta rápida a las familias y habitantes con problemas de acceso.

\section{LA DÉCADA DE LOS 80}

A partir de los años 80, se producen cambios significativos en la política de la vivienda en los países de la Europa del Norte. La necesidad de alojamiento está cubierta, el crecimiento de la población está

\section{VIVIENDA SOCIAL EN ALOUILER POR CADA 1000 HABITANTES 2007}

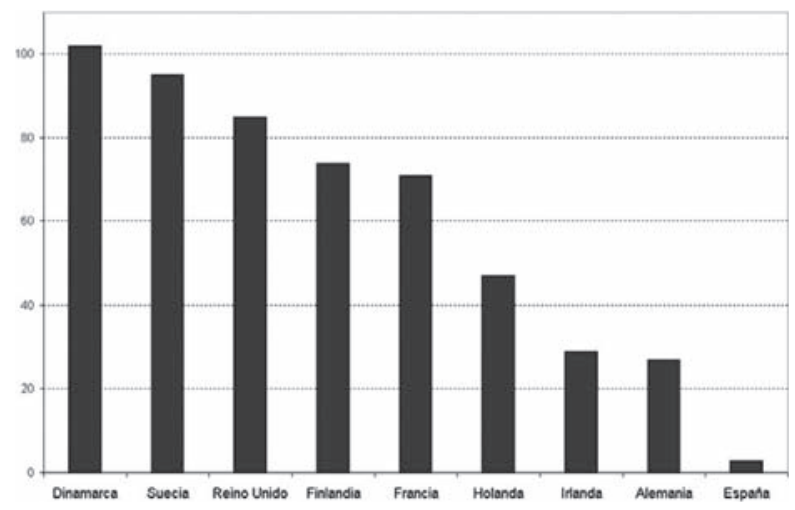

GRÁFICO 2

Fuente: CECODHAS (2007)

Elaboración propia.

estancado y algunos países empiezan a acercarse al crecimiento natural cero. Por otra parte, la crisis económica provoca importantes recortes en materia de vivienda. Tras liberalizar por completo el mercado del alquiler, muchos países optarán por potenciar la propiedad como régimen de tenencia y por conservar un pequeño porcentaje de vivienda social. Las ayudas a la producción se reducen notablemente, en beneficio de las ayudas a la persona. Por último, la crisis del petróleo trae consigo una nueva forma de interpretar las actuaciones dentro de la ciudad consolidada. 
Hasta los años 80 el crecimiento de la población era el resultado de un saldo vegetativo positivo, existiendo más nacimientos que muertes. Sin embargo, el descenso de la natalidad provoca el riesgo del crecimiento cero salvado por la inmigración, que en muchos países compensa el envejecimiento de la población: Alemania, Dinamarca, España, Grecia, Italia, Portugal y Suecia. Sin la inmigración, Alemania e Italia hubieran visto disminuir su población ya en 1996.

La apuesta por la propiedad como régimen de tenencia mayoritario desde la política de vivienda es una tendencia que empieza a barajarse desde los años 80. Algunos de los países analizados valoran que el coste en vivienda social es excesivo y que en muchos casos ha perdido su sentido original ya que gran parte de la población tiene recursos para acceder a la vivienda. Como consecuencia de ello, en 6 de los 9 países analizados tienen más de la mitad del parque de viviendas en propiedad, quedando tan sólo Dinamarca, Alemania y Suecia con más de la mitad del parque con otros regímenes de tenencia (Gráfico 3). España encabeza esta tendencia con un $82 \%$ de las viviendas en propiedad, seguido por Irlanda (79\%), Reino Unido (69\%) y Finlandia (63\%). Aunque en los años 50 el parque de viviendas ocupadas por sus propietarios en España no llegaba al 50\%, la política de vivienda franquista apostó por la propiedad frente a otros regímenes de tenencia, consolidándose la propiedad como única forma de acceso durante los años 70, situación que no ha sido corregida desde entonces. Además en España el alquiler social es prácticamente inexistente, por lo que el incremento de propietarios va siempre en detrimento del alquiler libre.

A partir de los años 80 , los poderes públicos reducen el número de construcciones de viviendas sociales. En algunos países como Irlanda y el Reino Unido comienzan a reducir las inversiones en el sector social, mientras que en otros como Holanda y Suecia se mantiene la política de inversiones. También se ponen en marcha medidas que van encaminadas a reducir el stock de vivienda social, lo que supone un considerable ahorro del presupuesto estatal en vivienda, como en Reino Unido o Irlanda. En el Reino Unido el gasto de la vivienda social se juzgó excesivo. Se puso en marcha el programa Right to Buy que consistía en ofrecer a los inquilinos la compra a precio moderado de las viviendas sociales que todavía eran gestionadas por las autoridades locales. En estos momentos la vivienda social queda casi exclusivamente en manos de las Housing Associations. En Irlanda se pone en marcha un sistema de propiedad compartida llamado "Shared Ownership" propuesto por las autoridades locales: el que adquiere la vivienda tiene la posibilidad de comprar al menos el $40 \%$ del valor de ésta con un interés bonificado, mientras se le da en alquiler la parte no adquirida de la vivienda. Por tanto y como se puede apreciar en el Gráfico 3 y en el Gráfico 4, desde 1980 en Reino Unido e Ir- 


\section{RÉGIMEN DE TENENCIA DEL PAROUE DE VIVIENDAS PRINCIPAL 1980}

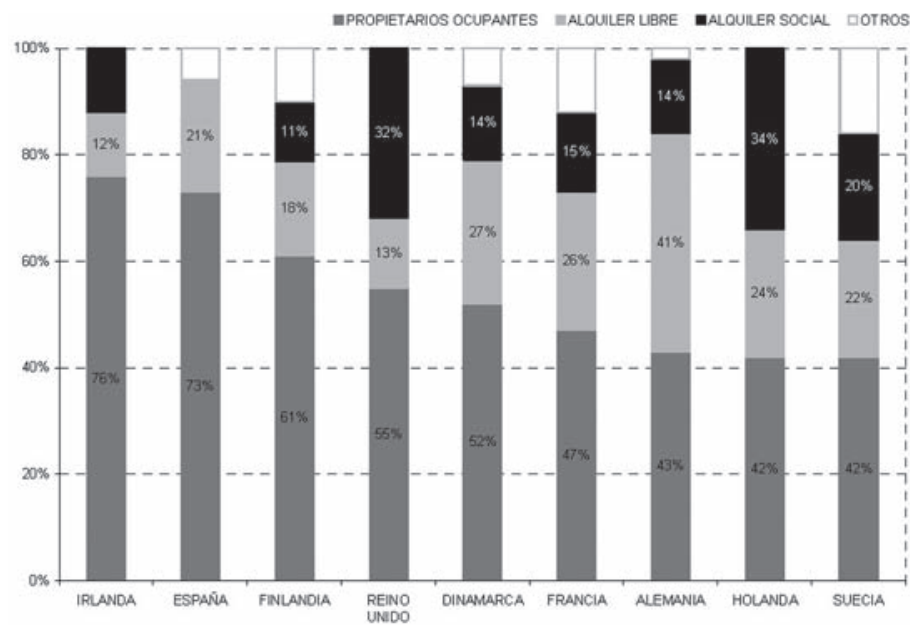

GRÁFICO 3

Fuente: FEDERCASA (2006) y Haffner, M.E.A. et C.P. DOLOTB Research Institute for Housing, Urban and Mobility Studies Delft University of Technology (2000).

Elaboración propia.

landa la propiedad aumenta de forma considerable en claro detrimento del alquiler social.

Con objeto de incentivar la compra de vivienda, lo que supone a largo plazo también un ahorro del presupuesto estatal, se reducen considerablemente las ayudas a la producción que son sustituidas por ayudas a la persona y por beneficios fiscales. Las ayudas a la persona se centran en gran medida en la rehabilitación de viviendas y barrios, con objeto de paliar la baja calidad de los tejidos urba-

134 revista invi № 69 / Agosto 2010 / Volumen № 25: 125-159 nos construidos en la época anterior y los nefastos efectos que tuvo la congelación de los alquileres sobre el parque más antiguo.

La primera crisis del petróleo y el estado del parque en alquiler empiezan a plantear dudas sobre las soluciones más adecuadas ante los problemas de la ciudad, ¿renovación o rehabilitación?, incluso entre la necesidad de construcción de más viviendas, o la conservación en buen estado de las ya existentes. 


\section{RÉGIMEN DE TENENCIA DEL PARQUE DE VIVIENDAS PRINCIPAL 2004}

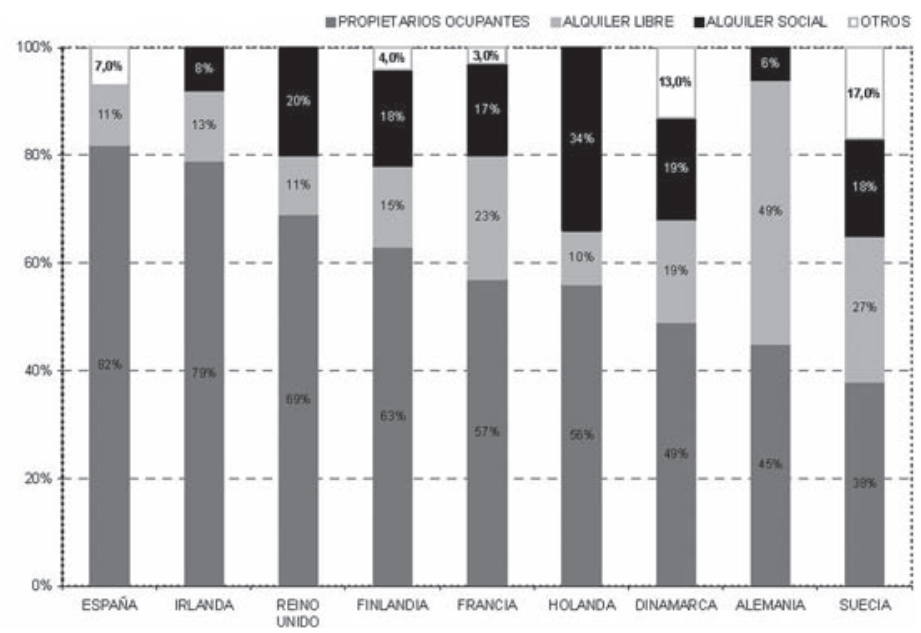

GRÁFICO 4

Fuente: FEDERCASA (2006)

Elaboración propia.

En el informe "Les principales tendances de la politique du logement dans les pays de la CEE", elaborado por Naciones Unidas en los años 80, se plantea ya la disquisición entre demolición y reconstrucción o rehabilitación como un problema vigente en esa época en los países de la Comunidad Económica Europea. Partiendo del análisis económico del problema, ¿qué es más rentable demoler y reconstruir o rehabilitar?, la respuesta inmediata es la rehabilitación. Pero el informe ahonda en el problema incluyendo otros factores además del económico: la crisis del petróleo y la consecuente subida de precios del transporte y los materiales o el notable incremento del paro en el sector de la construcción. La demolición y posterior reconstrucción de las viviendas en mal estado es mucho más caro energéticamente. Por otro lado, la rehabilitación de viviendas emplea mucha más mano de obra. Estas dos razones por sí solas serían suficientes para optar por la rehabilitación de viviendas. A estos factores se une el análisis de las prácticas habituales en la época sobre los tejidos 
urbanos degradados, tomando como referencia algunas de las leyes aprobadas en la década de los 50, como la Ley de Saneamiento en Dinamarca, que promueve la renovación urbana desde el punto de vista de la demolición y posterior reconstrucción. Los barrios más antiguos de las ciudades, sobre los que se habían aplicado mayoritariamente la congelación de los alquileres, son los más afectados por las políticas de renovación urbana. No obstante, estos tejidos urbanos, contrariamente a los nuevos barrios construidos durante la postguerra, se caracterizan por ser capaces de agrupar distintos servicios, gran variedad de usos y de clases sociales, y un patrimonio representativo de las diversas culturas, factores que no se encuentran en las nuevas agrupaciones residenciales construidas en la postguerra. Además, los ejemplos de renovación urbana habían traído como consecuencia problemas de realojo y graves procesos de expulsión; la población residente en estos barrios degradados se caracteriza por ser población de escasos recursos económicos. La renovación del parque de viviendas implicaba su revalorización y los nuevos precios superan el poder adquisitivo de sus habitantes, provocando su expulsión. Por tanto esta población, lejos de mejorar su calidad de vida gracias a la renovación, pierde su hábitat y se ve obligada a emigrar a zonas con condiciones parecidas a las anteriores, generándose un proceso de

136 revista invi № 69 / Agosto 2010 / Volumen № 25: 125-159 exclusión social. La rehabilitación, pues, se plantea como una vía más sostenible económicamente, socialmente y ambientalmente, que deberá contar con la participación de los habitantes de la ciudad. A continuación se esbozan algunas de las fechas significativas dentro de la renovación del pensamiento $^{10}$ (tabla 2).

Dinamarca junto con Holanda, Reino Unido y Francia encabezan en Europa los procesos de rehabilitación y regeneración de la vivienda, mientras que en España la construcción se sigue centrando en la creación de nuevas viviendas. Baste observar el Gráfico 5, en el que se ve que el nivel de construcción de viviendas en España es superior al de Francia, donde además se rehabilitan más viviendas de las que se construyen.

El aumento del paro, fruto de la crisis económica, y el abandono del parque de alquiler libre y el fomento de la propiedad provocan un aumento en la demanda de la vivienda social a lo largo de los años 80 . Sólo en Alemania y Suecia es fácil el acceso al alquiler libre.

\section{LA DÉCADA DE LOS 90}

A principios de los 90 todos los países de Europa se ven influidos por la crisis inmobiliaria, pero en algunos países como Irlanda y sobre todo España, este proceso se enmarca en un contexto de fuerte

10 Roca Caldera, Juana, 1996. 


\section{FECHAS SIGNIFICATIVAS DENTRO DE LA RENOVACIÓN DEL PENSAMIENTO}

\section{Siglo XIX}

Las primeras leyes de intervención en el Centro Histórico aparecen a finales del XIX:

La noción de protección del monumento surge a la vez, o como consecuencia de las medidas higienistas, derribos de edificios insalubres, para realizar avenidas grandes, luz, soleamiento (Haussman).

Años 30. Reforma legislativa en toda Europa.

Años 50 y 60 . Se inician las grandes operaciones de renovación urbana en los centros históricos.

1962. Francia. Ley Malraux.

Es la primera ley en defender los centros históricos de las políticas de renovación, introduciendo la protección no sólo en los monumentos, sino también en la arquitectura doméstica, pero sin tener en cuenta ningún aspecto social.

\section{Reino Unido. Housing Act.}

La escasez de viviendas impulsa la política de rehabilitación. Se ponen en marcha una serie de subvenciones para inquilinos y propietarios ocupantes que tienen por objeto la mejora integral de la vivienda, la dotación de servicios mínimos como baños interiores, agua corriente y agua caliente y de sistemas contra incendios.

1969. Ley de Saneamiento, Dinamarca.

1973. Suecia. Loi sur la modernisation de I'habitation.

1976. España. Ley del Suelo.

Se introducen nuevas figuras de planeamiento a utilizar dentro de la ciudad histórica.

1976-1990. Alemania. Programa sobre la modernización y renovación del patrimonio arquitectónico.

Se establecen dos tipos de ayudas para la rehabilitación:

- subvenciones a los propietarios ocupantes con un límite de renta o a los propietarios de viviendas con inquilinos con la condición de no subir el alquiler después de la reforma por encima del límite correspondiente a la vivienda social y

- ayudas para la modernización y ahorro energético del parque.

1975. Año europeo del patrimonio arquitectónico, Amsterdam.

1983. Dinamarca. Ley de rehabilitación.

TABLA 2

Fuente: Elaboración Propia 


\section{RELACIÓN ENTRE LA CONSTRUCCIÓN Y LA REHABILITACIÓN DE VIVIENDAS EN ESPAÑA Y FRANCIA 1993-1999}

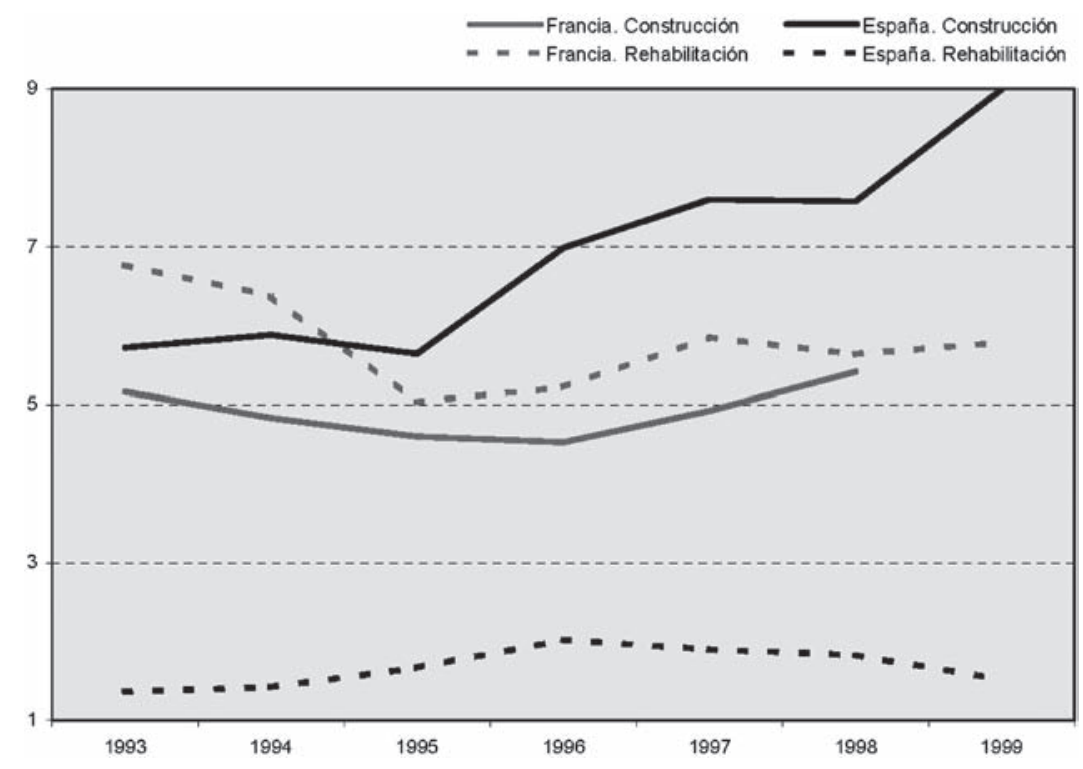

GRÁFICO 5

Fuente: Instituto Nacional de Estadística y Ministère de l'équipement.

Elaboración propia.

crecimiento económico y descenso del paro (ver gráfico 6).

Durante esta época, la tasa de construcción varía en sentido inverso al Producto Interior Bruto por habitante de los países analizados ${ }^{11}$. Cuanto menor es la riqueza del país, mayor es la construcción de

11 Louvot-Runavot. Op cit. viviendas. Con este comentario se daría a entender que mientras en los países de la Europa del norte la construcción de viviendas y el gasto público está ligado al gasto social y es recortado debido a las normas de convergencia de la Unión Europea, en los países del sur, donde el mercado de construcción de viviendas está desligado de este aspecto, el 


\section{CONSTRUCCIÓN DE VIVIENDAS, 1990-2007. VIVIENDAS POR CADA MIL HABITANTES}

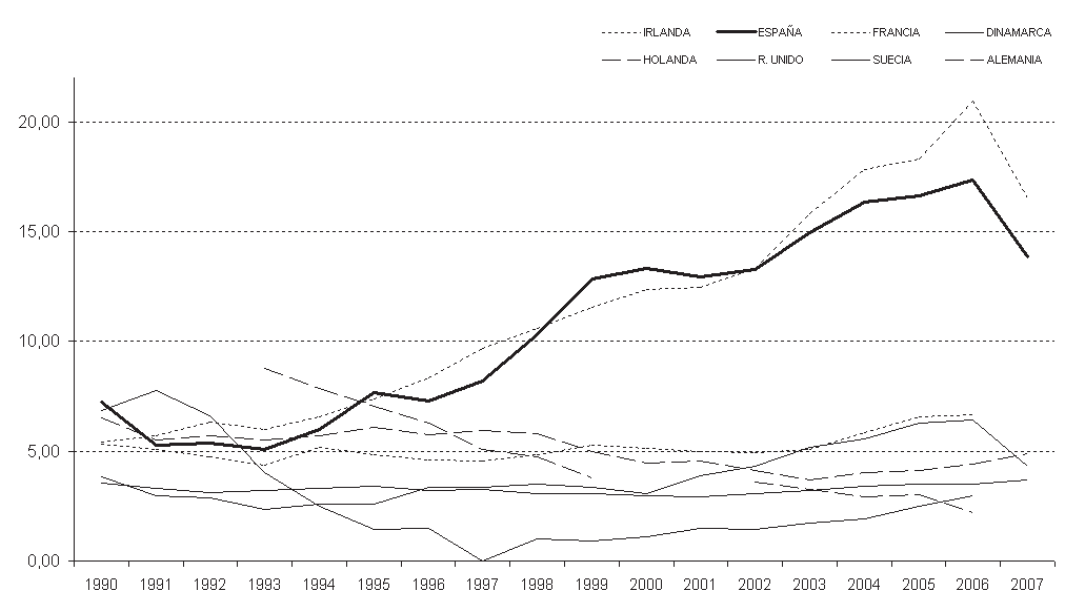

GRÁFICO 6

Fuente: Institutos de Estadística de los distintos países analizados.

Elaboración propia.

mercado de la construcción es utilizado para hacer crecer la riqueza, lo que implica también un cambio dentro del concepto de uso de la vivienda, no como bien de primera necesidad sino como valor de inversión, como valor especulativo ${ }^{12}$.

En Suecia y Holanda aparece una relativa regresión del sector social y posteriormente el presupuesto desciende en Francia y Dinamarca. Esta reducción paulatina en toda Europa tiene como origen el objetivo de la convergencia económica fijada en Maastricht, lo que puede dar a entender que esta situación es temporal. Suecia, Reino Unido y Holanda (puede ser debido a un cambio de ideología, causa que sería en principio también temporal) reducen la inversión en vivienda como consecuencia de todos los problemas acumulados por la política anterior: localización de las subvenciones, segregación social y calidad de las viviendas y los barrios.

12 Naredo, 2000 
Durante los años 90 se generaliza el fomento al acceso a la vivienda en propiedad a través de ayudas fiscales. La financiación de la vivienda en propiedad se basa en dos puntos: el Ahorro de los hogares y los Créditos bancarios.

Todos los países tienen instituciones especializadas que distribuyen créditos para la vivienda y tienen como función recolectar los ahorros familiares con el fin de financiar la construcción residencial.

Salvo Irlanda y el Reino Unido, todos los países han puesto en marcha sistemas de "ahorro-vivienda" que favorecen la inversión inmobiliaria y la compra de viviendas a través de intereses altos o primas en el ahorro y/o préstamos posteriores con intereses reducidos.

Las formas de ayuda más habituales son la reducción fiscal sobre los intereses de los préstamos hipotecarios, la exoneración del impuesto sobre los bienes inmuebles y, en la mayoría de los países, la ausencia de tasas en la venta de viviendas.

\section{CONSECUENCIAS Y DEFICIENCIAS A FINALES DE LOS AÑOS 90}

Las deficiencias que a continuación se detallan han sido extraídas del informe W14 "La politique du logement dans l'Union Européenne". Las conclusiones de este informe, elaborado en la segunda mitad de los 90, momento de crisis económica en
Europa, son, por un lado, el punto de partida para el análisis del principio del siglo XXI y por otro, bastante representativos de los problemas existentes a día de hoy en España.

\section{Propiedad}

Los hogares en régimen de propiedad tienen mayores rentas que los hogares en régimen de alquiler. Sin embargo, en los países mediterráneos, con mayor índice de propietarios ocupantes, existe un porcentaje notable de población que, a pesar de ser propietarios, se encuentran en dificultades económicas:

- Personas mayores cuyas viviendas en propiedad no están adaptadas a sus necesidades.

- Personas mayores de escasos recursos económicos propietarias de viviendas con problemas de rehabilitación, mantenimiento.

- Pérdida de empleo y dificultad para pagar la vivienda. En la década de los 90 se señalaba Reino Unido y Finlandia como los países más significativos. Actualmente, con la crisis económica muchos hogares residentes en España están en esta situación.

- Separación y divorcio: demanda de vivienda en alquiler.

Las políticas fiscales que benefician la compra de viviendas son accesibles para las clases medias y 
altas que se trasladan a barrios residenciales, generando una ciudad dividida por rentas.

Además, la población de menor renta queda excluida de estas ayudas, agudizándose la situación en los países donde el resto de alternativas es escaso. Como ejemplo podemos citar una de las reformas sobre el Impuesto de la Renta de las personas físicas anunciadas por el Gobierno Español para el ejercicio 2003, que planteaba una deducción de hasta el 25\% de las rentas obtenidas por el alquiler de vivienda. Esta medida parecía favorecer la puesta en el mercado de las viviendas vacantes. Sin embargo, no intentaba controlar el precio del alquiler, esperando que con el aumento de la oferta, los precios disminuyeran, perdiendo de nuevo una ocasión para dar solución a las familias con menos recursos.

\section{AloUiler privado}

Existen datos que demuestran que los inquilinos en este régimen tienen menor renta que los propietarios y mayor que los habitantes del parque social. No obstante se detectan algunas situaciones de riesgo:

- Hogares de la tercera edad sin ingresos residiendo en viviendas en malas condiciones.

- Jóvenes hogares y solteros con bajos ingresos en paro o que han dejado la familia por situación violenta o desaparición.
- Hogares inmigrantes y minorías étnicas sin ingresos para acceder a la propiedad y sin posibilidad de acceder a la vivienda social.

Un alto porcentaje de este parque está situado en los centros de las zonas urbanas, representando más del doble del índice nacional y el triple en las capitales.

En Holanda y el Reino Unido la baja en este tipo de oferta ha sido muy importante en los últimos años debido a las políticas emprendidas por los diferentes países:

- Grandes demoliciones

- Subvenciones destinadas a otros sectores

- Reglamento de alquiler muy estricto.

En Alemania, sin embargo, las ayudas fiscales a los propietarios han hecho posible mantener un parque de muy buena calidad. Además en Francia y Alemania existen primas y ayudas fiscales para este tipo de inquilinos.

En cuanto a las políticas de rehabilitación hay que destacar las emprendidas en Dinamarca, Holanda y Reino Unido que están llevando a cabo operaciones de regeneración. Las viviendas en mal estado en régimen de alquiler privado son adquiridas por entidades sin ánimo de lucro que gestionan el parque de vivienda social para su posterior rehabilitación y/o la adaptación a las necesidades particulares de personas mayores, o disminuidos físicos, etc. 


\section{VIVIENDA SOCIAL Y EXCLUSIÓN ESPACIAL}

La exclusión no es sólo un problema de los centros de las grandes ciudades sino que se extiende a las áreas de vivienda social (Dublín, París, Londres, Copenhaguen, Berlín...). Cuando estos barrios se construyeron los hogares residentes contaban con bajos recursos pero la tasa de empleo era muy alta. Las perspectivas de los residentes actuales han disminuido en gran medida al ser la población mayoritariamente afectada por la reconversión industrial, formada en su mayoría por mano de obra no cualificada y envejecida. En la década de los 90, la vivienda social alojaba a la población de mayor riesgo: parados, familias monoparentales, minorías étnicas e inmigrantes que estaban concentrados en determinadas áreas de la ciudad.

La vivienda ha dejado de ser un problema para el conjunto de la sociedad y la política de vivienda se reorienta hacia iniciativas que solucionen el contexto complejo de los más desfavorecidos. En Francia, Reino Unido, Irlanda, Dinamarca, Holanda y Suecia se han puesto en marcha programas de rehabilitación de barrios gestionados por un partenariado entre el sector público, el privado y la colectividad.

142 revista invi № 69 / Agosto 2010 / Volumen № 25: 125-159
La inversión y gestión de las viviendas se integran con acciones en el campo social, sanitario y medioambiental (Dundee, Rotterdam o Lyon).

\section{ACTUALES OBJETIVOS DE LA POLÍTICA DE VIVIENDA EN EUROPA}

El derecho a la vivienda y el reconocimiento de ésta como bien de primera necesidad se recoge por primera vez en 1948 en la Declaración Universal de los Derechos Humanos. Más de cincuenta años después la vivienda sigue siendo un problema en muchos lugares. En este contexto, la Conferencia sobre los Asentamientos Humanos Hábitat II, celebrada del 3 al 14 de junio de 1996 en Estambul, recoge una serie de compromisos bajo el lema Una vivienda adecuada para todos. La Unión Europea, a pesar de no tener competencias directas sobre esta materia ${ }^{13}$, se adhiere a estos compromisos traduciendo las propuestas de la cumbre al contexto europeo: proporcionar seguridad en la tenencia, promover el derecho a una vivienda digna, proporcionar igualdad de oportunidades en el acceso a la propiedad del suelo, promover la igualdad de oportunidades en el acceso al crédito y promover

13 Según el principio de subsidiaridad, la Unión Europea no tiene competencia en materia de vivienda y los países miembros tienen plena libertad para regular y legislar. Los fondos estructurales, cuyo objeto es la solución de problemas económicos, no pueden utilizarse en proyectos de inversiones en vivienda con objetivo social que sustituirían el presupuesto estatal (principio de adicionalidad). 
el acceso a los servicios básicos. Repasando las diferentes legislaciones europeas, el objetivo común de las políticas en todos los países se podría resumir en la misma premisa: el derecho de todos los ciudadanos a acceder a una vivienda digna.

Una vez solucionado el problema masivo del acceso a la vivienda, los países europeos tienden a fomentar la propiedad como forma de acceso, con objeto de que la vivienda no sea una carga económica para el Estado en el caso de las clases medias. A partir de entonces, la política de vivienda se centra en nuevas dimensiones como son: la capacidad de elección haciendo referencia tanto a la diversidad en el régimen de tenencia como a la cohesión social y a la variedad de clases sociales, edades y circunstancias en los enclaves de vivienda como es el caso de Francia, Finlandia, Irlanda o el Reino Unido; o el derecho no sólo a la vivienda sino también a un entorno saludable, seguro y ecológicamente sostenible, el derecho a la ciudad, a un medio ambiente sano y el derecho a la calidad de vida (Suecia, Francia, Irlanda o Finlandia); o el derecho a una vivienda con un precio razonable en el caso de Suecia o Finlandia. En este sentido la vivienda deja de ser un derecho a garantizar por sí sólo y se empieza a entender como parte activa y fundamental de otras materias:

- La política contra la exclusión social, en la que hay que destacar la importancia de la vivienda. La mezcla de clases sociales como forma de lu- cha contra la segregación espacial, la inclusión de las nuevas necesidades específicas de determinados grupos sociales, resultado de una nueva estructura de la población (inmigrantes, tercera edad, jóvenes o minusválidos), o los procesos de participación dentro de la gestión de las viviendas como método de integración social son algunos de los aspectos que aparecen en las distintas políticas europeas.

- La política de la ciudad desde un punto de vista sostenible y medioambiental que prime el cuidado del entorno y de la ciudad existente frente al crecimiento desmedido cuyo principal exponente es la rehabilitación integrada de barrios.

\section{Breve historia de la política de vivienda en España}

\section{LA CREACIÓN DEL PAROUE DE VIVIENDAS EN ESPAÑA. LA ÉPOCA DEL DESARROLLISMO}

En España la construcción masiva de vivienda se produce casi dos décadas después que en los países del norte de Europa. Así, los primeros planes de vivienda redactados formaban parte de los Planes de Desarrollo Económico y Social que se llevaron a cabo durante la última época del franquismo. En aquel momento el principal objetivo era cubrir la necesidad de vivienda de forma genérica: el parque 
de viviendas era demasiado pequeño y se iniciaba una serie de procesos sociales, como la emigración campo-ciudad, a los que había que dar respuesta de forma inmediata. Estos planes recogen una estimación del número de viviendas necesarias (demanda) para albergar a la población española y fijan unos objetivos para la construcción de viviendas tanto libres como sociales. Al terminar la dictadura, el principal objetivo se había cumplido. El tamaño del parque de viviendas se considera un tema menor, pasando a ser prioritario garantizar el acceso a la vivienda a los hogares y personas con menos recursos a través de la construcción de viviendas protegidas. Por tanto, la construcción masiva de viviendas, que en Europa duró aproximadamente tres décadas, en España se concentró entre 1964 y 1976, es decir, un tercio del tiempo empleado en Europa.

Paralelamente a la puesta en marcha de los Planes de Desarrollo Económico y Social se aprueba una nueva ley sobre arrendamientos urbanos (1964), que mantenía la congelación sobre los alquileres. Este régimen de tenencia no era, por tanto, un objetivo de la política de vivienda y todas las viviendas que se construyeron durante esos años estaban destinadas a ser ocupadas por sus propietarios.

El Plan de Vivienda 1961-1976, incluido dentro de los Planes de Desarrollo Económico y Social, toma

144 revista invi № 69 / Agosto 2010 / Volumen № 25: 125-159 la decisión de apoyar la construcción de viviendas como una de las alternativas para comenzar el despegue económico del país. Y esta decisión, que se repite constantemente desde los años 60 hasta el día de hoy, es un factor determinante en la política de vivienda en España, marcando la principal diferencia con el resto de países analizados.

La inclusión de este plan en los Planes de desarrollo económico y social determina no sólo la vinculación del sector de la construcción con el desarrollo económico del país sino también con la industria del turismo. En 1963 se aprueba la Ley de Centros y Zonas de Interés Turístico Nacional única y exclusivamente para dar cabida a los complejos hoteleros eliminando las competencias de los municipios, que ven en esta medida un problema, a la vez que la oportunidad de aumentar su recaudación y la riqueza del municipio ${ }^{14}$.

La emigración campo-ciudad, el incremento de las rentas familiares y la política de vivienda, que pretende hacer de cada español un propietario, provocan el aumento de la demanda de viviendas. En el periodo 1961-1976 se construyen muchas más viviendas de las que el plan señalaba como necesarias, pero en régimen libre, quedando el número de viviendas protegidas construidas por debajo de las determinaciones del plan. Es en este momento en el que se produce el gran aumento de viviendas

14 González Berenguer, 1979; Parejo, 1979; Nasarre, 1972. 
vacías y secundarias. Como se puede apreciar en el Gráfico 7, en 1981 las viviendas principales representaban el 70\% del parque de viviendas total, con una disminución de 22 puntos respecto al censo de 1960. Las viviendas secundarias pasan de 3.3\% a $12.8 \%$ y las vacías de $4.3 \%$ a $16.2 \%$. Aunque parte de este cambio puede ser producido por la emigración campo-ciudad, puede también comprobarse cómo en el censo de 1981 las viviendas vacías y secundarias se concentran tanto entre las más viejas (anteriores a 1941) como entre las más nuevas: de las viviendas construidas entre 1971 y 1980, sólo el 62\% era vivienda principal.

Cuando sobreviene la crisis del petróleo, la carencia en materia de vivienda sólo afecta a unos pocos, los más desfavorecidos, y la capacidad de construcción en esta época se reduce considerablemente no sólo por la coyuntura económica sino por la situación política por la que atraviesa España.

\section{LA DÉCADA DE LOS 80}

El siguiente Plan de Vivienda (Plan trienal 19811983) vuelve a plantear dos objetivos de la misma naturaleza: el descenso del paro y dar cobertura a esa parte de la población que no había podido optar a una vivienda durante la época anterior. Pero el plan vuelve a fracasar, manteniendo de forma endémica un porcentaje de población sin acceso

ARTíCULO: La política de vivienda en España en el contexto europeo. Deudas y retos / Raquel Rodríguez A. a la vivienda. La mala situación económica incrementa la demanda de viviendas sociales que van siendo acaparadas por clases más acomodadas con mayor capacidad para obtener un crédito. Por otro lado, no existen previsiones desde el punto de vista de la localización, de modo que muchas de las viviendas que se construyen no son necesarias ${ }^{15}$.

Y analizando el Plan cuatrienal 1984-1987 podemos observar cómo la historia vuelve a repetirse. A pesar de que este plan incluye medidas que intentan acercar la política de vivienda en España a la coyuntura europea, como son el fomento de la rehabilitación, la entrada en el Mercado Común Europeo vuelve a ser una excusa para intentar impulsar el desarrollo del país a través de la industria de la construcción. En 1985 se aprueba el Decreto Boyer cuya intención es la de sentar las bases para un crecimiento estable y duradero de la economía española como condición necesaria para crear empleo. Dentro de una serie de medidas de política económica cuyos objetivos son estimular el consumo privado y la inversión, fomentar el empleo e impulsar el sector de la construcción ${ }^{16}$, aparecen dos de vital importancia en materia de vivienda: la desaparición de la congelación de los alquileres y la desgravación en vivienda cualquiera que sea su destino final, es decir, tanto si se usa como si se deja vacía (la deducción por adquisición de vivien-

15 Pedro, 2000.

16 Exposición de motivos del Real Decreto Ley. 


\section{EVOLUCIÓN DEL USO DEL PARQUE DE VIVIENDAS EN ESPAÑA 1950-2001}

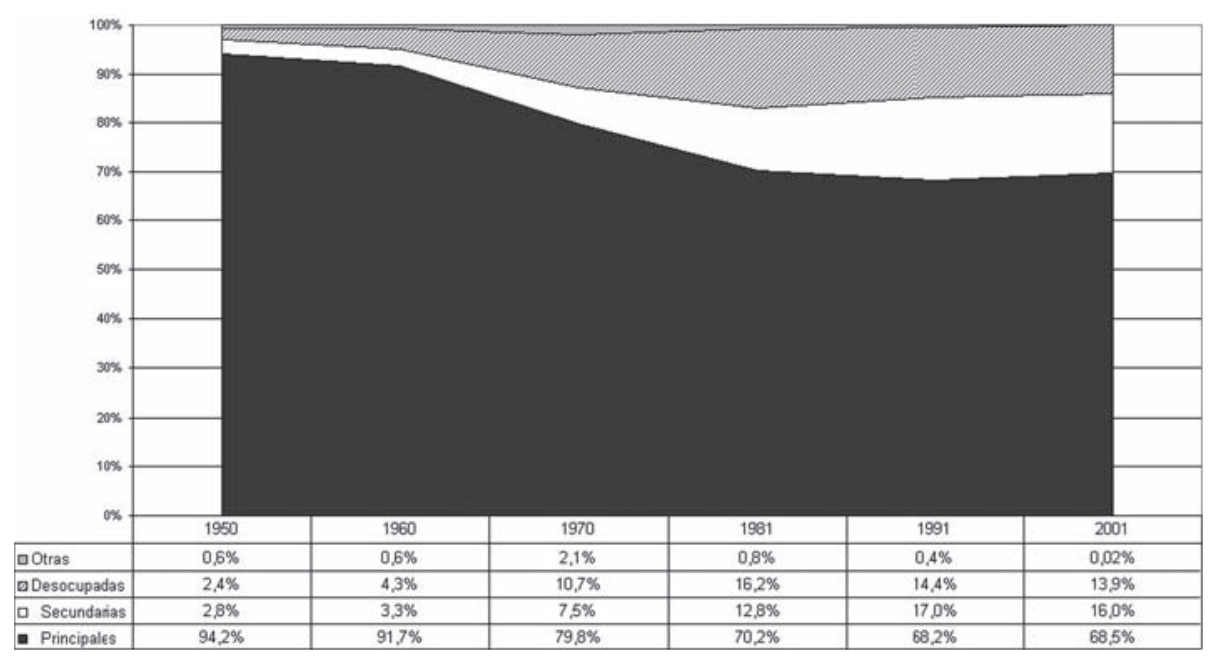

GRÁFICO 7

Fuente: Censos de Población y vivienda (INE)

Elaboración propia.

da es el segundo mecanismo de incentivo accesible a cualquier persona física, con un componente nítidamente definido, de expansión del sector de la construcción $^{17}$ ). Como resultado de esta medida, entre 1981 y 1991 el parque de viviendas secundarias se incrementa en un $43 \%$, acrecentando uno de los mayores problemas del parque de viviendas en España: su infrautilización que lo caracteriza respecto al modelo europeo analizado (ver Grá-

17 Ibid.

146 revista invi № 69 / Agosto 2010 / Volumen № 25: 125-159 fico 8). Según los últimos datos disponibles, sólo se utilizaba como vivienda principal el $68.5 \%$ del parque, quedando el resto del stock, $31.5 \%$, como vivienda vacía o segunda residencia.

Aunque la descongelación de los alquileres se produce en todos los países estudiados en momentos similares, con una coyuntura económica óptima en la que no tiene sentido mantener esta situación, el 


\section{EVOLUCIÓN DEL PORCENTAJE DE VIVIENDAS VACÍAS AÑOS 90-2000}

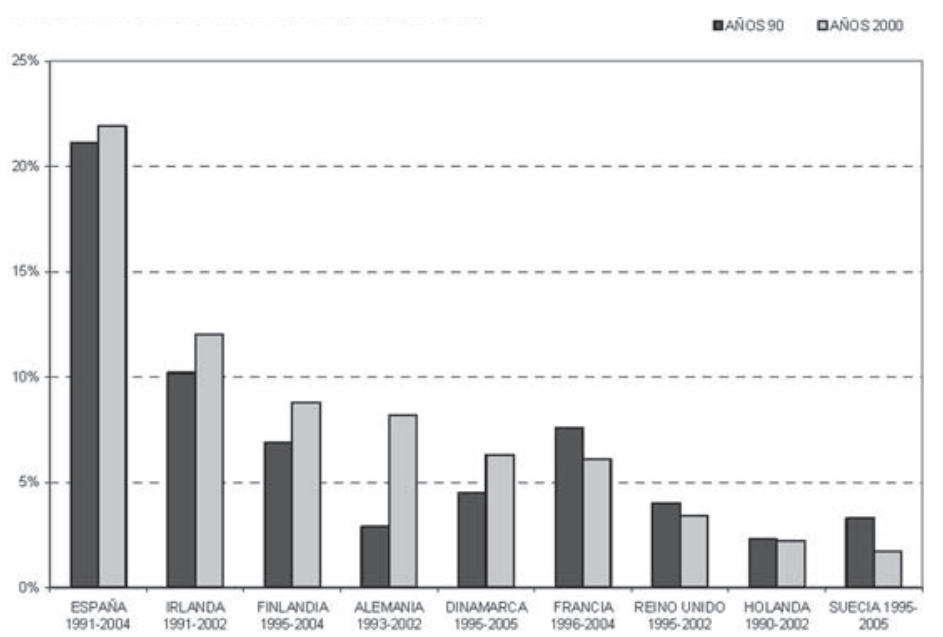

GRÁFICO 8

Fuente: FEDERCASA, 2006 y Haffner, M.E.A. et C.P. DOLOTB, Research Institute for Housing, Urban and Mobility Studies Delft University of Technology, 2000

Elaboración propia.

punto de partida en España no es el mismo. Por un lado existía en Europa una cultura de la promoción privada y pública de viviendas en alquiler y un sector económico consolidado que podía reaccionar en relativamente poco tiempo a las nuevas demandas. Por otro lado, la existencia de un abundante patrimonio gestionado por los entes públicos y privados garantizaba la posibilidad de alternativas para la población, que era capaz de percibir el alquiler como una oportunidad más, no como la única salida a un problema de insolvencia económica.

\section{LA DÉCADA DE LOS 90}

Entre los años 1998 y 2003, se aprueban una serie de medidas que recrudecen aún más la situación y que vuelven a reincidir en el mismo objetivo: impulsar la economía española a través de la industria de la construcción. Casi todas las ayudas diseñadas durante esta época tienen como destino una clase media capaz de invertir sus ahorros en la compra de una vivienda, olvidando por completo los problemas de acceso de los más desfavorecidos. 
En 1998 se elimina la desgravación por el alquiler de la vivienda en el Impuesto sobre la Renta, manteniendo la desgravación por la compra y optando de nuevo por la estrangulación dentro de las formas de acceso a la vivienda. Es decir, se penaliza fiscalmente el alquiler frente a la compra de vivienda, afectando mayoritariamente a las familias de menores recursos. Se ponen en marcha las Cuentas Ahorro Vivienda para menores de 35, que garantizan unos intereses por encima del mercado y la desgravación fiscal siempre que dicho ahorro se destine a la compra de vivienda en un plazo inferior a 4 ó 6 años. Como medida para regular el precio del suelo, la ley del suelo de 1998 define como urbanizable todo aquel suelo que no tenga características para ser urbano o no urbanizable. Como consecuencia, la construcción de vivienda libre y su precio se disparan. Según los datos de Eurostat, España está entre los tres países donde más ha crecido el precio de la vivienda nueva entre 1997 y 2008, junto con Irlanda y Finlandia, con un incremento de 50 puntos en menos de 10 años (1997 -2006). Como se puede apreciar en el Gráfico 9, los países en los que menos aumenta el precio de la vivienda coinciden con aquellos en los que existe un menor porcentaje de viviendas principales ocupadas por sus propietarios (Alemania, Holanda, Francia y Dinamarca). España e Irlanda, dos de los países donde más aumenta el precio de la vivienda, tienen en común dos características: el mayor crecimiento del parque en el mismo periodo (88 y 97 viviendas más por cada 1000 habitantes) y el mayor porcentaje de propietarios en todo el grupo analizado (82\% y $79 \%$, respectivamente).

A pesar del incremento en el precio de la vivienda, España destaca por ser uno de los países donde menos ha crecido el índice del precio de la construcción residencial. Esto significa que el incremento en el precio no tiene relación con la subida de precios de los materiales ni de la mano de obra empleados en la construcción de la vivienda. Teniendo en cuenta que los mayores gastos en la producción inmobiliaria residencial son la mano de obra, el precio de los materiales, el valor del suelo y el beneficio del promotor, podemos deducir que el crecimiento del precio de la vivienda es consecuencia del aumento del precio del suelo y/o del beneficio del promotor, ambas condiciones vinculadas a la especulación inmobiliaria. La escasez de suelo, argumento ampliamente utilizado para justificar la subida de su valor, no es ni ha sido un problema en los últimos 10 años. La ley del suelo estatal de 1998 determina que sólo es suelo no urbanizable el suelo que tenga características especiales para su conservación, haciendo legalmente viable e impulsando políticamente el desarrollo urbano en todo el suelo que no cumpla estas características. Esto ha provocado la creación de un volumen de suelo cada año que permite tripli- 


\section{EVOLUCIÓN DEL PRECIO DE LA VIVIENDA NUEVA 1997-2008 (2000=100)}

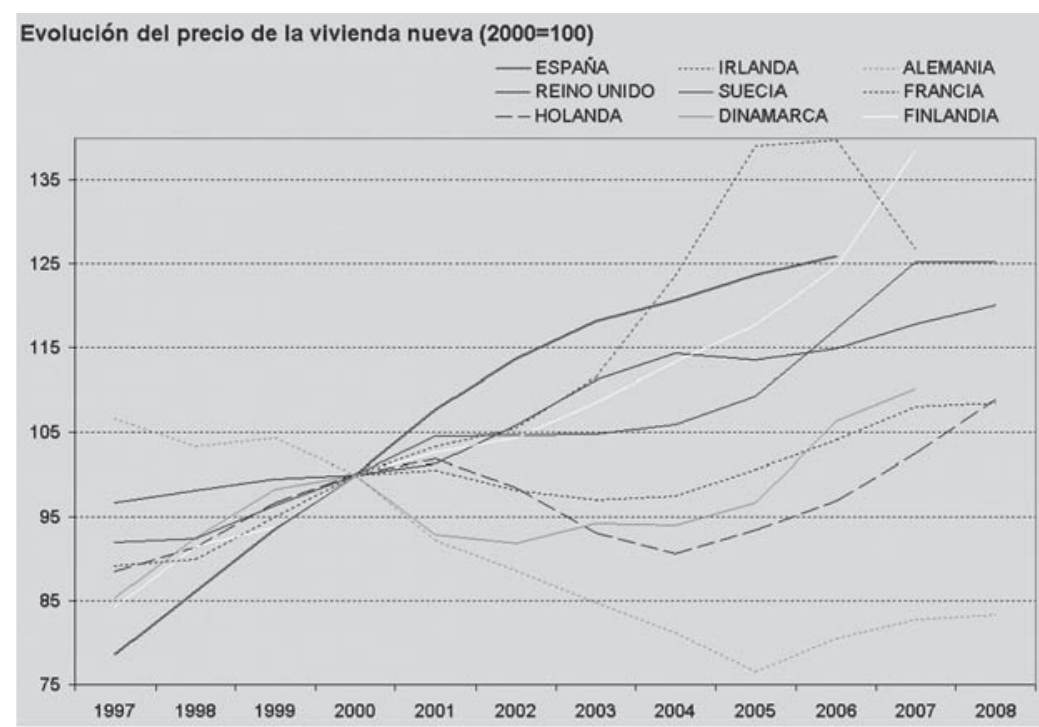

GRÁFICO 9

Fuente: Eurostat.

Elaboración propia.

car el número de viviendas construidas ${ }^{18}$. El precio del suelo se establece en función de lo que en él vaya a desarrollarse. Por tanto, el incremento del precio de la vivienda en España no parece responder a ninguna premisa que no esté vinculada a la especulación, impidiendo el acceso a la vivienda en contra de los dispuesto en el artículo 47 de la Constitución Española.

18 Naredo. Op cit.

\section{POLÍTICA DE VIVIENDA EN ESPAÑA EN EL CONTEXTO EUROPEO}

La relación existente entre la industria de la construcción y el desarrollo económico de un país es descrita, entre otros, por Ramón Tamames ${ }^{19}$ que señala que en España dicha industria representa el 15\% del producto industrial, el 5\% del Producto

19 Introducción a la economía española, 1986. 
Interior Bruto y proporciona trabajo a más del 10\% del total de la población activa ${ }^{20}$. La construcción de viviendas es sólo parte de esta industria, pero tanto su peso como su influencia sobre la economía no es nada desdeñable. Dentro de las políticas económicas de los sucesivos gobiernos españoles, el impulso a la construcción de viviendas será una constante que ha influido de manera perversa sobre la formación de la estructura del parque de viviendas actual. En todos los planes de vivienda aprobados, los objetivos pretendidos tienen doble naturaleza: por un lado, se presentan como la forma de satisfacer la demanda social existente, paliando la necesidad de vivienda; por otro, este propósito va siempre acompañado de objetivos económicos globales ajenos a la política de vivienda ${ }^{21}$.

Como hemos visto, mientras que en Europa conseguir un parque de viviendas adecuado a las necesidades de la población y reorientar los objetivos de la política costó casi 30 años, en España el proceso se produjo mucho más tarde y con mucha más rapidez. Las aspiraciones del país en ese momento estaban orientadas al desarrollo económico. Mientras que en Europa el proceso fue más lento y acompasado, y la evolución se produjo en una región mucho más amplia, cuando España afronta el reto sola, y encamina todas sus decisiones, las de

20 González Moreno, Miguel.

21 González Moreno, Miguel. Véase también los objetivos de los Planes de Vivienda 1961-1976 y 1981-1983 o la exposición de motivos del Real Decreto ley 2/1985 (Decreto Boyer).

150 revista invi № 69 / Agosto 2010 / Volumen № 25: 125-159 calado social también, hacia un rápido desarrollo económico. Por tanto, mientras el objetivo de los países europeos estuvo orientado a la búsqueda de un bienestar social en sí mismo, en España dicho bienestar se confundió con el mero desarrollo económico. Algunas de las decisiones tomadas en ese momento transforman profundamente la estructura del parque y, a pesar del tiempo transcurrido, siguen definiendo la situación actual:

- Se fomentó el acceso a la vivienda en propiedad, frente a los modelos europeos que diversificaron las formas de acceso, al menos en sus inicios.

- No se planteó la creación de un parque de viviendas social sino que se pasó directamente a la construcción y venta directa de las viviendas protegidas.

En los siguientes 40 años, la política podría haber sido reorientada. Sin embargo, como ya hemos visto, en diversos momentos en los que era necesario apostar por un repute de la economía por diferentes motivos (entrada en la Comunidad Económica Europea en 1985, Proceso de Convergencia para la Unión Económica y Monetaria Europea en 1999, mantenimiento de los requisitos del pacto de Esta-

ARTÍCULO: La política de vivienda en España en el contexto europeo. Deudas y Retos /

Raquel Rodríguez A. 
bilidad y Crecimiento), los gobiernos de distintos signos vuelven a apostar por el impulso de la construcción residencial como motor económico.

Cuando los objetivos de los planes de vivienda son tan dispares se está poniendo en juego el valor de uso de la vivienda ${ }^{22}$, en beneficio de su valor de cambio. La vivienda se transforma en objeto de inversión, los precios aumentan a mayor ritmo que el poder adquisitivo de la población y aparece un sector del parque cuyo fin no es el de ser utilizado sino que se ha transformado en objeto de acumulación ${ }^{23}$. Paralelamente a este proceso, la población más desfavorecida va quedando al margen.

Bajo esta premisa la política de vivienda ha utilizado la construcción como motor de crecimiento tanto en los momentos de bonanza, como de crisis económica. La doble intencionalidad de los planes y políticas de vivienda acaba haciendo depender la coyuntura económica del sector de la construcción, muy sensible a los momentos de crisis. En periodos de bonanza, el aumento de las rentas familiares genera un incremento de la demanda que inclina la balanza hacia la construcción de viviendas libres dejando a parte de la población sin acceso y provocando un aumento de los precios que repercute también sobre el precio de las viviendas de régimen protegido, dando lugar a una espiral de especulación que sólo parará cuando sobrevenga

22 Ídem. Para mayor detalle ver Sánchez Martínez, María Teresa.

23 Naredo. Op. cit. el periodo de crisis. En estos periodos el Gobierno intenta rehacer la política, pero de nuevo son las clases más acomodadas, con mayor facilidad para optar a créditos hipotecarios ${ }^{24}$, las que acaparan las viviendas que se construyen. El sistema de ayudas empleado por el Estado para la construcción de viviendas protegidas no compensa en momentos de bonanza económica, ya que los rendimientos por la construcción de viviendas libres superan con creces la rentabilidad de las viviendas sociales. De este modo, sea cual sea la coyuntura económica, parece haber una tendencia a que las viviendas se desvien hacia la población de más renta, quedando el sector de la población más desfavorecido al margen del acceso a la vivienda, a pesar de la existencia de un parque lo suficientemente grande como para dar cabida a toda la población residente en España. Esta situación perpetúa una demanda oculta de viviendas, mientras que gran cantidad del stock que sale al mercado se desvía hacia la inversión, creándose un parque infrautilizado. Como podemos apreciar en el Gráfico 10, mientras que en Alemania, Dinamarca, Finlandia, Holanda, Reino Unido y Suecia la diferencia entre la capacidad del parque y el tamaño del hogar están más o menos ajustados, con una diferencia de 0.1 en la mayoría de los casos, en España la diferencia se dispara. Mientras que el tamaño del hogar es de

24 La propiedad como única forma de acceso hace este proceso mucho más intenso. 
2.9 personas, la capacidad del parque de viviendas es de 1.9 habitantes por vivienda. Esto supone unas 8.4 millones de viviendas de más.

Paralelamente, la situación del parque en alquiler, única alternativa para algunos sectores de población, es mucho peor que el parque en propiedad. La congelación de los alquileres y los incentivos fiscales a la compra van convirtiendo el parque de viviendas en alquiler en residual, manteniéndose como la alternativa para aquellos hogares cuyos recursos no les permitan acceder a la propiedad. Una política basada en un sólo régimen de tenencia, la propiedad, desanima tanto a los inversores potenciales como a los dueños de las viviendas sin uso, de modo que el parque en alquiler va reduciéndose en número y está en peores condiciones. Desaparecen las opciones de elección que en determinadas situaciones son muy importantes: divorcios, movilidad de la población por trabajo, emancipación de los jóvenes.

Además de instrumentos como la fiscalidad, la política de vivienda se ha regulado a través de herramientas urbanísticas que actualmente están muy lejos de conseguir un consumo de suelo moderado y un desarrollo de la ciudad acorde con las necesidades reales que garantice el acceso a la vivienda. El crecimiento urbano y la construcción de viviendas no guardan ninguna relación con las necesidades reales. Se siguen aprobando planes generales que proponen crecimientos desmedidos respecto a la población y al número de viviendas existente. No existen apenas limitaciones legales que impidan macizar el territorio y las restricciones al crecimiento surgen de ámbitos ajenos al urbanismo. El crecimiento urbano queda sólo limitado por las áreas naturales protegidas, quedando otros problemas como garantizar el suministro de energía o agua como meros problemas técnicos y de inversión económica.

No sólo se construyen más viviendas de las precisas en número sino que ni siquiera se garantiza que su uso, su precio y a veces su tipología o ubicación vayan a ser las que correspondan con las necesidades reales. Son el mercado y la demanda, muchas veces basados en la inversión y no en el uso, los que deciden qué, cuánto y cómo se construye y ni la legislación urbanística, ni los planes de vivienda, ni los incentivos fiscales ni los planes generales están diseñados para contrarrestar las decisiones del sector inmobiliario. Es el mercado el que decide el tipo de cliente al que va dirigido el producto inmobiliario. Mientras parte de la población tiene serias dificultades para acceder a la vivienda, la estructura legal vigente y el motor económico del mercado hacen más sencillo y más rentable la promoción de viviendas de lujo o viviendas secundarias asociadas a campos de golf que la construcción de viviendas asequibles.

Ante el desmedido desarrollo urbano de los últimos años que ha recrudecido el problema de ac-

ARTÍCULO: La política de vivienda en España en el contexto europeo. Deudas y Retos / 


\section{DIFERENCIA ENTRE EL TAMAÑO DE LOS HOGARES Y LA CAPACIDAD DEL PAROUE DE VIVIENDAS. 2005}

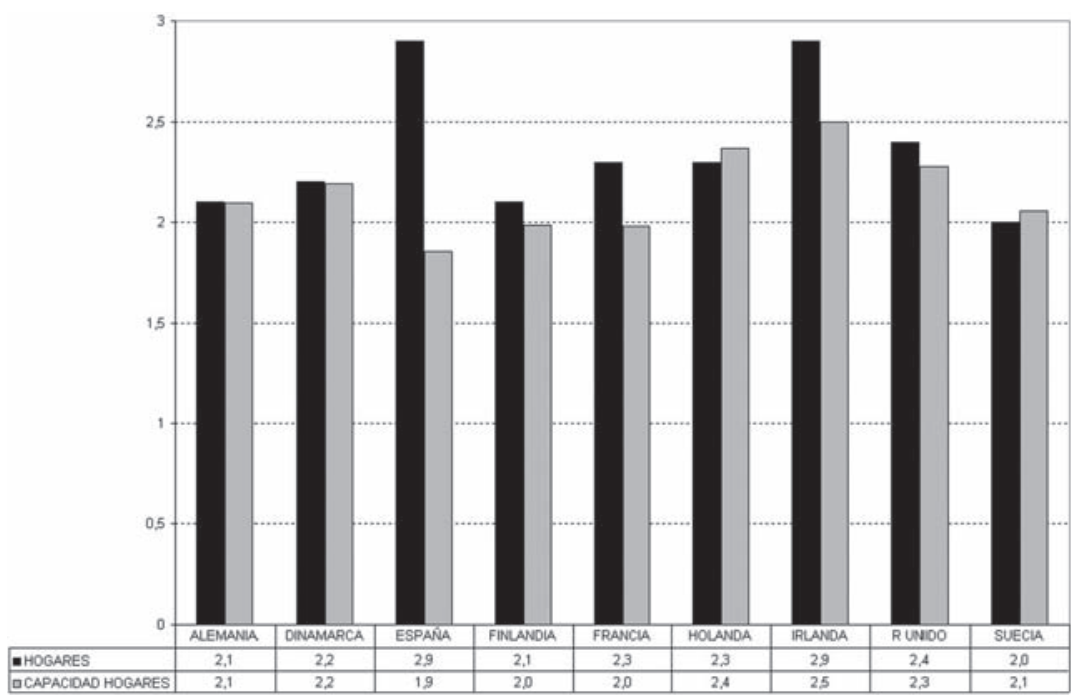

GRÁFICO 10

Fuente: FEDERCASA (2006) y Estadísticas de población de EUROSTAT.

Elaboración propia.

ceso de determinados sectores de población, la nueva ley estatal del suelo obliga a reservar suelo para la construcción de viviendas con algún tipo de protección. Pero la reserva de suelo no significa el desarrollo de éste, por lo que el mercado sigue teniendo capacidad de poner en marcha aquellas promociones que le resulten más rentables según el ciclo económico. Por otro lado, la estandarización de una cifra global para todo el territorio con un destino ambiguo, vivienda con algún tipo de protección, reincide en la falta de análisis de las necesidades reales de cada territorio.

La reserva de suelo tampoco afronta otro de los problemas que persisten en las ciudades actuales: la segregación espacial y la formación de enclaves de población socialmente excluida. La apuesta por un parque de viviendas en propiedad y el abandono sistemático de las viviendas en alquiler han propiciado la construcción de una ciudad en la que 
los habitantes están organizados por su capacidad de renta. El precio de la vivienda no depende tanto de sus características físicas como de la zona urbana en la que está ubicada ${ }^{25}$. Frente al desmedido desarrollo urbano y la construcción de viviendas de lujo vinculadas a campos de golf, siguen existiendo enclaves con graves deficiencias urbanas y un parque de viviendas en mal estado en los que residen habitantes de bajos recursos económicos y con problemas sociales. Reducir el problema del acceso a la vivienda a ayudas económicas y reservas de suelo perpetúa el modelo existente, que segrega económicamente y socialmente a la población y construye para quien puede pagar, no para quien lo necesita. No existen herramientas que fomenten la cohesión social y el desarrollo de una ciudad heterogénea, y los objetivos del mercado, y muchas veces de los poderes públicos, están lejos de afrontar este tipo de retos.

\section{Conclusiones y buenas prácticas}

Un parque sobredimensionado y mal repartido, en el que las familias de mayor renta acaparan varias viviendas mientras existe población con problemas de acceso, la generación de tejidos urbanos de buena y mala calidad, con procesos de exclusión so-

25 Roch, 2003

154 revista invi № 69 / Agosto 2010 / Volumen № 25: 125-159 cial endémicos o la ausencia de alternativas para el acceso a la vivienda para los hogares que no tienen recursos para acceder a la compra son problemas comunes en materia de vivienda. A continuación se ponen de manifiesto algunas medidas que servirían para contrarrestar los principales problemas en materia de vivienda en aquellos casos, como el español, en los que la política no ha conseguido garantizar el acceso a la población más desfavorecida.

\section{MEDIDAS CONTRA LA INFRAUTILIZACIÓN DEL PAROUE DE VIVIENDAS}

En Francia y Suecia se han puesto en marcha mecanismos cuyo objetivo era sacar de nuevo al mercado el parque de viviendas vacante. En el trasfondo de dichas medidas están las mismas premisas: no tiene sentido que el Estado invierta en vivienda cuando parte del parque, ya sea privado o público, está sin uso, siendo esta situación especialmente gravosa en aquellos lugares en los que existen problemas de acceso y/o calidad del parque de viviendas habitado.

En Francia el problema parece estar situado en las grandes aglomeraciones, donde existe una importante demanda de vivienda. Según se señalaba en el resumen ejecutivo de la aprobación de la Ley contra la exclusión social2 ${ }^{26}$, en 1998 un total de

26 Loi n $98-657$ du 29 juillet 1998. 
2,5 millones de personas estaban mal alojadas mientras que existían un total de 2 millones de viviendas vacantes, 840.000 de las cuales estaban situadas en las grandes aglomeraciones, donde la demanda de viviendas era cada vez mayor. Ante esta situación se ponen en marcha dos tipos de medidas: las que incentivan la puesta en valor del parque a través de ayudas, como el Contrato de Rehabilitación ${ }^{27}$ con el que la administración francesa realiza subsidiariamente las obras necesarias dentro del inmueble a cambio de su uso por un tiempo mínimo de 12 años, y las que penalizan al propietario. Desde 1998, se grava con un impuesto aquellas viviendas que permanezcan voluntariamente vacantes durante un periodo superior a dos meses y estén situadas en aglomeraciones de más de 200.000 habitantes en las que exista un desequilibrio entre la oferta y la demanda de viviendas y una tasa de viviendas vacantes elevada. El dinero recaudado se reinvierte en rehabilitación. En los casos de inmuebles vacíos con problemas de rehabilitación, el Prefecto de la Región puede acceder a requisar dichos inmuebles con objeto de, una vez rehabilitados, destinarlos a personas con rentas modestas y personas desfavorecidas.

En Suecia, las viviendas vacantes son habitualmente consecuencia del incremento de la tasa de paro en determinadas regiones que llevan a la población

27 Artículo L. 252-1 del Código de la Construcción y la habitación (artículo 11 de la ley 90-449 del 31 de mayo de 1990). a trasladarse a otros lugares en busca de empleo, afectando en mayor medida al parque social. Los alquileres en la vivienda social se calculan sobre la base de los costes de la totalidad del parque perteneciente a cada entidad sin ánimo de lucro en el municipio. El objetivo es dividir estos costes entre todas las viviendas alquiladas atendiendo a criterios estándar que dependen del tamaño de la vivienda y su calidad. El aumento del número de viviendas vacantes se estaba traduciendo en un aumento del alquiler para los inquilinos, de modo que en los casos de la población de menor renta la situación empezaba a ser paradójica. Las medidas adoptadas son diversas: descuentos en el precio del alquiler para atraer a nuevos habitantes, reutilización de las viviendas para otros usos, incluso demolición de parte del parque vacante.

\section{DIVERSIFICACIÓN DE LAS FORMAS DE ACCESO A LA VIVIENDA}

Además de la apuesta por la creación de un parque social en alquiler cabe destacar la existencia de otro tipo de régimen de tenencia, entre la propiedad y el alquiler, que tiene una presencia importante en los países escandinavos, Suecia, Dinamarca y Finlandia: las cooperativas o condominios. Se basan en el derecho a ocupar una vivienda de una cooperativa que ostenta la titularidad de uno o 
más edificios multifamiliares o unifamiliares. Los miembros de la cooperativa son los representantes de las unidades familiares correspondientes, cada una de las cuales posee una parte del total que le da derecho a ocupar una determinada vivienda, pagando a la cooperativa una entrada proporcional al tamaño de la misma y una cuota mensual. Destaca además la participación de los inquilinos en la gestión del parque de viviendas.

En Finlandia los cooperativistas o shareholders pueden ser personas físicas, jurídicas o entidades sin ánimo de lucro. Esto significa que en una misma Housing Companie, es decir, que en un mismo bloque de viviendas pueden existir inquilinos con ayudas o sin ayudas, viviendas sociales, viviendas en alquiler, etc. Debido a la variedad de shareholders posibles dentro de estas sociedades, la diversidad de situaciones económicas y circunstancias sociales es lo suficientemente grande como para facilitar la mezcla y la convivencia de los distintos sectores sociales.

\section{MEDIDAS CONTRA LA SEGREGACIÓN ESPACIAL}

La vivienda social en alquiler en Alemania sólo representa el 6\% del total del parque y disminuye poco a poco. Sin embargo, los Ayuntamientos siguen teniendo la obligación de alojar a los hogares más necesitados. Para ello, desde 2001 el sistema

156 revista invi № 69 / Agosto 2010 / Volumen № 25: 125-159 social se basa en el uso del parque privado existente a través de un convenio particular entre el propietario y el ayuntamiento fijando un precio por debajo del mercado. A la vez el parque de vivienda social, propiedad de los municipios, se va vendiendo a organizaciones de inquilinos. Esta medida fomenta la mezcla de clases sociales al menos dentro del parque de alquiler, forma de acceso mayoritaria en Alemania.

En Dinamarca, la política de viviendas social sigue el modelo universal, de modo que está disponible para cualquiera, aunque los ayuntamientos tienen una reserva del 25\% del parque para cubrir las necesidades de los hogares desfavorecidos. El alquiler se fija en función del coste y las viviendas se adjudican por lista de espera. Una de las características de la vivienda social en Dinamarca es el carácter democrático de los inquilinos que está regulada por ley desde 1984. Cada sección es responsable del presupuesto, mantenimiento y gestión de las partes comunes.

En Irlanda la ley sobre planificación, desarrollo y vivienda obliga a los promotores privados a incluir dentro de sus proyectos una parte que irá destinada a vivienda social, a un precio asequible que se fija en colaboración con las autoridades locales.

En Francia el artículo 55 de la Ley de Solidaridad y Renovación Urbana ${ }^{28}$ establece la necesidad de que

28 Loi n 2000-1208 du 13 décembre 2000. 
todas las entidades locales con población superior a los 3.500 habitantes situados en aglomeraciones urbanas superiores a los 50.000 tengan al menos un $20 \%$ de vivienda social en alquiler sobre el total del parque principal. El no cumplimiento de esta determinación supone una retención del presupuesto equivalente al 20\% del potencial fiscal por habitantes por cada vivienda no realizada.

\section{Bibliografía}

CARRASCO PERERA, ÁNGEL Y PÉREZ DE CASTRO, NAZARET. Arrendamientos Urbanos. Propiedad horizontal y legislación Complementaria. Madrid, España, Editorial Civitas, Biblioteca de Legislación. 1992. 310 p. ISBN 84-470-0212-8.

GARCÍA MONTALV0, JOSÉ; et al. Financiación de la vivienda. Perspectivas del sistema financiero. Madrid, España, Fundación de las Cajas de Ahorros Confederadas para la Investigación Económica y Social, 2003, 163 p. ISSN: 1132-95. González Berenguer, José Luís. Gestión, Financiación y Control del Urbanismo. Madrid, España, Instituto de Estudios de la Administración Local. 1979. 964 p ISBN: 84-7088-235-X

GONZÁLEZ MORENO, MIGUEL (dir). Temas de economía española. Valencia, España. Tirant lo Blanc Libros, 1998. 448 p. ISBN: 84-8002-591-3.

HAFFNER, M.E.A. ET C.P. DOLOTB. Research Institute for Housing, Urban and Mobility Studies Delft University of Technology Statistiques du loge- ment dans l'Union Européenne [En línea]. Ministère Néerlandais du logement, de l'aménagement du territoire et de l'environnement de présenter la brochure à temps au Sommet des Ministres du Logement de l'UE qui s'est déroulé en France en septembre 2000. [Fecha de consulta: 25 de mayo de 2010] Disponible en: http://www.ebst.dk/ file/2256/housing_statistics_2003.pdf

INSTITUTO NACIONAL DE ESTADÍSTICA (INE). Censos de población y viviendas 1981 [En línea]. Instituto Nacional de Estadística, 1981. [Fecha de consulta: 25 de mayo de 2010] Disponible en: http://www.ine.es/jaxi/menu.do?type=pcaxis\&p ath $=\% 2 \mathrm{Ft} 20 \% 2 \mathrm{Fe} 241 \&$ file $=$ inebase $\& \mathrm{~L}=$

------ Censos de población y viviendas 1991 [En línea]. Instituto Nacional de Estadística, 1991. [Fecha de consulta: 25 de mayo de 2010] Disponible en: http://www.ine.es/jaxi/menu.do?type=pcaxis\&p ath=\%2Ft20\%2Fe243\&file=inebase $\& \mathrm{~L}=$

------ Censos de población y viviendas 2001 [En línea]. Instituto Nacional de Estadística, 2001. [Fecha de consulta: 25 de mayo de 2010] Disponible en: http://www.ine.es/jaxi/menu.do?type=pcaxis\&p ath $=\% 2 \mathrm{Ft} 20 \% 2 \mathrm{Fe} 242 \&$ file $=$ inebase $\& \mathrm{~L}=$

JUÁREZ, MIGUEL (dir.). «Vivienda», en V Informe sociológico sobre la situación de la vivienda en España. Sociedad para todos en el año 2000. Fundación Foessa (Fomento de Estudios Sociales y de sociología aplicada), volumen II, capítulo 10, 1994 (pp 1551-1729).

LOUVOT-RUNAVOT, CLAUDIE. Le logement dans l'Union européenne: la propriété prend le pas 
sur la location. [En Línea] Istitute Narional de la Statistique et des Études Économiques, ÉCONOMIE ET STATISTIQUE N 343, 2001 - 3 [Fecha de consulta: 25 de mayo de 2010] Disponible en: http://www.insee.fr/fr/ffc/docs_ffc/es343b.pdf

MINISTERIO DE FOMENTO. Dirección General de la Vivienda, la Arquitectura y el Urbanismo, El acceso a la propiedad principal en la Unión Europea. Madrid, España. Ministerio de Fomento. Serie Monografías, 1997. 95 p. ISBN: 84-498-0328-4.

------ Plan de Vivienda 1998-2001 [En línea] Boletín Oficinal del Estado del 26 de junio de 1998 n 152 [Fecha de consulta: 25 de junio de 2010] Disponible en: http://www.boe.es/boe/dias/1998/06/26/ pdfs/A21249-21269.pdf

------Atlas estadístico de las áreas urbanas en España [En Línea] Ministerio de Fomento. Serie Monografías 2000 [Fecha de consulta: 25 de junio de 2010] Disponible en: http://www.mviv.es/es/pdf/ otros/atlas.pdf

------ Índice de precios de las viviendas. Estadística de precio medio del $\mathrm{m}^{2}$ Madrid, España, Ministerio de Fomento. Dirección General de Programación económica, 2001. 99 p. ISBN: 84-498-0621-6.

MINISTERIO DE OBRAS PÚBLICAS, Transportes y Medio Ambiente (MOPTMA). Informe Nacional de España Hábitat II [En línea]. Boletín CF+S, Documentos 1996 [Fecha de consulta: 25 de junio de 2010] Disponible en: http://habitat.aq.upm.es/in
----- Transportes y Medio Ambiente (MOPTMA) (1995) «Gobiernos Nacionales, Ciudades y Sociedad ante la Conferencia Hábitat II, Istambul 1996. Nota Introductoria a la Reunión de Comités Nacionales de la Unión Europea», Reunión regional europea de los Comités Hábitat [En línea]. Boletín CF+S, Documentos, noviembre de 1995 [Fecha de consulta: 25 de junio de 2010] Disponible en: http://habitat.aq.upm.es/rech/a003.html

NACIONES UNIDAS. Les principales tendances de la politique du logement dans les pays de la CEE, Comité de vivienda, construcción y planificación de la CEPE. Naciones Unidas, 1980.

NAREDO, JOSÉ MANUEL. Composición y valor del patrimonio inmobiliario en España 1990-1997. España, Madrid, Ministerio de Fomento. Secretaría General Técnica. 2000, 85 p ISBN: 84-498-0465-5.

NASARRE ALASTRUEY, RAFAEL. Las urbanizaciones particulares. La ley del suelo ante el fenómeno turístico. Madrid, España, Editorial Montecorvo, 1972. $208 \mathrm{p}$

PAREJO ALFONSO, LUCIANO. La ordenación urbanística. El periodo 1959-1975. Madrid, España, Editorial Montecorvo S.A, 1979, 299 p.

PARLAMENTO EUROPEO. (1996). La politique du logement dans les États membres de l'Union Européenne [En línea]. Direction Générale des Études (W14 décembre 1996) [Fecha de consulta: 25 de junio de 2010] Disponible en: http://www.europarl.europa. eu/workingpapers/soci/w14/text2_fr.htm

ARTÍCULO: La política de vivienda en España en el contexto europeo. Deudas y Retos / 
PEDRO, AURORA. Espacio urbano y política de vivienda. Valencia, España. Generalitat Valenciana. Conselleria d'Obres Publiques, Urbanisme i Transports. Colección Tesis Doctorals, 2000.

ROCA CLADERA, JUANA; et al. Rehabilitación urbana: análisis comparado de algunos países de la Unión Europea (Alemania, Bélgica, Dinamarca, Francia, Italia y Portugal), Madrid, España, Centro de Publicaciones, Secretaría General Técnica, Ministerio de Obras Públicas, Transportes y Medio Ambiente, 1995.

SÁNCHEZ MARTíNEZ, Ma TERESA. La política de vivienda en España, análisis de sus efectos redistributivos. Granada, España, Universidad de Granada, Biblioteca de Económicas y Empresariales, 2002. 441 p. ISBN 84-338-2830-4.

TAMAMES, RAMÓN. Introducción a la economía española ( $16^{\circ}$ edición), Madrid, España, Alianza Editorial, 1986. 580 p. ISBN: 84-206-1090-9.

TRILLA, CARME. La política de vivienda en una perspectiva europea comparada, Barcelona, España, Fundación La Caixa, Colección de Estudios Sociales de La Caixa (noveno volumen), 2001. 208 p. ISBN: 84-88099-82-7. 